\title{
Primer encuentro «Diálogo norte-sur: estudios latinoamericanos»
}

\section{Vincent Gouëset}

\section{(Q) OpenEdition}

\section{Journals}

Edición electrónica

URL: http://journals.openedition.org/bifea/3979

DOI: $10.4000 /$ bifea.3979

ISSN: 2076-5827

\section{Editor}

Institut Français d'Études Andines

Edición impresa

Fecha de publicación: 1 diciembre 2006

Paginación: 455-456

ISSN: 0303-7495

\section{Referencia electrónica}

Vincent Gouëset, «Primer encuentro «Diálogo norte-sur: estudios latinoamericanos» », Bulletin de I'Institut français d'études andines [En línea], 35 (3) | 2006, Publicado el 01 junio 2007, consultado el 01 diciembre 2020. URL : http://journals.openedition.org/bifea/3979; DOI : https://doi.org/10.4000/bifea. 3979

\section{(c) $(1) \odot$}

Les contenus du Bulletin de l'Institut français d'études andines sont mis à disposition selon les termes de la licence Creative Commons Attribution - Pas d'Utilisation Commerciale - Pas de Modification 4.0 International. 


\title{
PRIMER ENCUENTRO «DIÁLOGO NORTE-SUR: ESTUDIOS LATINOAMERICANOS»
}

\author{
Quito, Noviembre 8, 9, 10 de 2006
}

Tuve el gusto de participar en este acontecimiento, en representación del Instituto Francés de Estudios Andinos. El objetivo del Encuentro era de hacer un balance sobre el origen, el estado actual y las perspectivas de los Estudios Latinoamericanos (ELA) tanto en América Latina como en los países del Norte (Estados Unidos, Canadá y Europa occidental principalmente), cruzando las miradas disciplinarias.

El Encuentro puso en relieve el desigual estado de los ELA a través del mundo, siendo aquellos estudios bien representados en EEUU y Canadá (aunque con dificultades crecientes) o en México (UNAM entre otros), en desarrollo en varios países de América Latina (como en Colombia o en Ecuador, a través de la UASB), pero con ciertas dificultades en muchos países (en Inglaterra por ejemplo), por falta de respaldo institucional, entre otros. Se insistió sobre la necesidad de seguir trabajando, a pesar de la extrema diversidad del espacio regional, de la crisis de ciertos paradigmas «latinos» de las últimas décadas (Escuela de la Depedencia...), y de los cambios introducidos, a nivel teórico como empírico, por el actual proceso de globalización (que contribuye a redefinir las relaciones entre localidad y globalidad), a una escala latinoamericana, que sigue pertinente para entender los hechos sociales económicos, sociales o culturales a lo largo de la región. Sobran los ejemplos que lo demuestran: sincronización en el actual viraje político hacia la izquierda, convergencia en la emergencia del multiculturalismo y de voces indígenas o afro-descendientes, afán de integración regional (que no va sin plantear une serie de problemas similares), etc.

La cuestión disciplinaria también constituyó otro tema debatido: la mayoría de los centros que ofrecen unos currículos de ELA lo hacen en una perspectiva pluridisciplinaria (con una desigual presencia de cada disciplina, estando literatura o ciencias políticas, por ejemplo, mucho más representadas que geografía o incluso economía), pero eso no quiere decir que la cercanía de distintas disciplinas se traduzca por un auténtico proceso de «hibridación» entre las disciplinas, tanto en la docencia como en la investigación. La lógica institucional del sistema académico lo impide muchas veces, pero por otro lado, la necesidad de mantener una base disciplinaria sólida apareció como un requisito necesario, no solamente a nivel epistémico (para intercambiar entre disciplinas con bases conceptuales firmes), sino también pensando en las salidas profesionales de los estudiantes, más fáciles con una base disciplinaria claramente identificada.

Para terminar, el encuentro me permitió hacer hincapié sobre la evolución de los temas de investigación de la geografía francesa en América Latina, agrupándolos alrededor de una serie de grandes entradas: población, migraciones y movilidad, cuestión étnica, temática urbana, temática rural, ordenamiento territorial y reformas institucionales, medio ambiente y riesgos naturales, impactos socio-territoriales de la globalización y del cambio de modelo de desarrollo 
económico. También se discutió de la peculiaridad de la zona andina, donde se ha ilustrado con notorios avances la geografía francesa, a lo largo del último medio siglo y en unos campos muy variados, alrededor del IFEA y del IRD principalmente; unos estudios que siempre se enmarcan en un contexto latinoamericano, y que muchas veces se realizaron en un contexto pluridisciplinario.

\section{Vincent GOUËSET}

